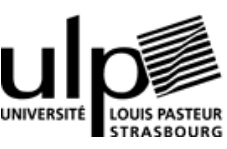

Laboratoire

de Recherche

en Gestion

\& Economie

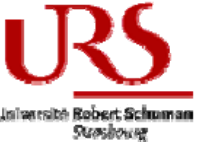

LAR LARGE

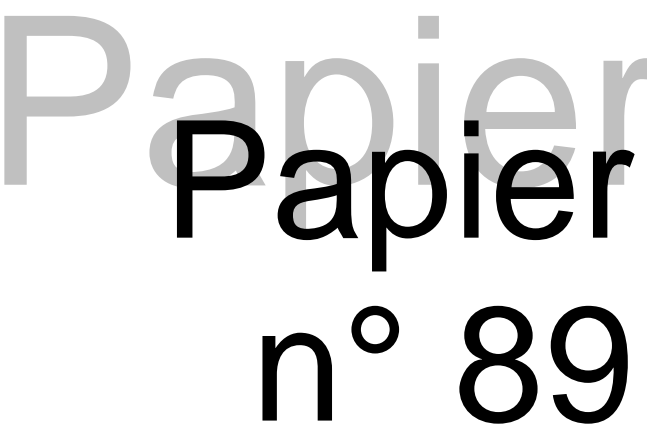

On the optimality of the full cost pricing

\author{
Jacques Thépot / Jean-Luc Netzer
}

Faculté des

Février 2007

sciences économiques

et de gestion

PEGE

61, avenue de la Forêt Noire 67085 STRASBOURG Cedex

Tél. : (33) 0390242152

Fax : (33) 0390242151

www-ulp.u-strasbg.fr/large

Institut d'Etudes Politiques 47, avenue de la Forêt Noire 67082 STRASBOURG Cedex 


\title{
On the optimality of the full cost pricing
}

\author{
Jacques Thépot and Jean-Luc Netzer \\ LARGE \\ Université Louis Pasteur \\ 61, avenue de la Forêt Noire \\ 67085 Strasbourg cedex \\ France \\ e-mail : thepot@cournot.u-strasbg.fr
}

February 13, 2007

\begin{abstract}
Most companies prefer to use absorption costing rule rather than marginal cost pricing. This article is aimed at defining the absorption costing rule as deriving from a principal-agent formulation of two tier organizations : (i) the upstream unit fixes the production capacity and uses it as a cost driver to compute the average cost (ii) the downstream unit operates on the market and chooses the output level on the basis of the average cost. Absorption costing results in two policies to be used according to the magnitude of the fixed cost. When the fixed cost is low, the capacity is fully used and a full cost pricing policy holds; when the fixed cost is high, a partial cost pricing policy holds since only a part of the fixed cost is passed on. The absorption costing rule competes with three pricing rules related to this two-tier structure and various payoffs functions associated to the decision levels: the separation, the tranfer pricing and the integration These rules are analyzed in the Cournot oligopoly case and comparisons in terms of profits are made. Except in the monopoly case, there exists a wide range of values of the fixed cost, for which the full cost pricing dominates all the other rules. In addition, there exists a specific value of the fixed cost for which the full cost pricing duplicates the monopoly and then leads to the first best solution of the Cournot oligopoly.
\end{abstract}

JEL Classification : D4, L22, M41.

Keywords : full cost pricing, imperfect competition.

Acknowledgement 1 We wish to thank Rodolphe. Dos Santos Ferreira, Alain Bultez, the session participants of the EARIE conference, Porto September 2005 and the FUCAM seminar, Mons, Belgium, February 2006, for helpful comments on earlier versions of this paper.

\section{Introduction}

Economic theory argues that the firm must use a pricing on the basis of marginal (or variable) cost, so that the fixed costs are not taken into account. In words, 
the consumer has not to bear the fixed cost which has to be deduced a posteriori from the firm's profit.

It is known that the firms are reluctant to accept this type of reasoning; Usually they prefer to fix the prices on a full or absorption cost basis. The surveys by Govindarajan \& Anthony (1983) and Shim \& Sudit (1995) on American manufacturing companies indicate that more than $60 \%$ of them use full-cost pricing. Such a divergence between the business practices and the theoretical recommendations is well known since the seminal article by Hall and Hitch (1939) (for a survey of the main contributions to this debate, see Lukas, 1999, cf. also Mongin, 1997).

Clearly the marginal cost pricing is historically related to integrated structures managed on a command and control basis to achieve productivity goals. This apparatus may be inappropriate in today's business world of the Modern Firm (Roberts, 2004) where the organizations, in search of flexibility, operate under delegation mechanisms and/or contracts between independent actors located overseas. Integration is no longer the dominant form of organization. In this context, the key role of the cost-based pricing rules has to be analyzed in terms of the incentives they produced within decentralized organizations operating in interaction with autonomous partners or rivals.

However absorption costing is always considered as a rule of thumb with poor conceptual background. The average cost of a product is usually based on a budgeted or expected quantity of output used to compute the average cost which may differ from the actual quantity sold once a cost based pricing rule is applied. The relationship between the budgeted and the actual quantity remains a black hole of the theoretical literature so that a formal definition of the absorption costing is missing. Our paper is aimed at clarifying this point.

We propose here a principal-agent formulation of the absorption costing rule: as we know, the marginal cost pricing derives from the profit maximization principle of the firm considered as an unique decision maker. Transposing this argument, the absorption costing will be defined here as the result of interrelated maximization problems involving subunits of the firm.

Hence the firm under consideration here is a two-tier organization in a deterministic environment where the upstream unit is in charge of providing a capacity of service or product to a downstream unit which runs the production capacity and sells on the market. In this context, it is quite natural to use the production capacity as the budgeted quantity. This is a reasonable point of view since in many industries, production capacity generates the greatest part of the fixed costs and is under the control of a specific subunit of the organization located at an upper level of the organization.

This two-tier structure resorts to various organizations analyzed in IO literature, e.g.: supply chain systems (e.g. Corbett and Karmarkar, 2001), divisional firms with production departments (or headquarters) as upstream and marketing departments (or profit centers) as downstream units (Zhao, 2000), network systems with providers of facilities as upstream and users as downstream units (Laffont, Rey and Tirole, 1998a and 1998b).

In this context, the absorption costing rule is embedded in a specific organization structure: the upstream unit incurs a fixed cost which covers the infrastructure expenditures and the overhead associated with the delivery of capacity. The downstream unit sells the output on the final market. The upstream unit fixes the production capacity and passes a part of the fixed cost on 
the downstream unit by charging him with a variable cost equal to the average cost of capacity. Clearly, the absorption costing competes with the pricing rules related to three typical vertical relations ${ }^{1}$ :

(i) The vertical integration, where the upstream and the downstream units are merged. This leads the firm to use the standard marginal cost pricing rule. (ii) The transfer pricing, where upstream unit charges a transfer price to the downstream unit; the upstream unit is in charge of maximizing the profit of the firm. (iii) The separation where the upstream unit charges a wholesale price to the downstream unit and the downstream unit seeks to maximize his specific profit. This induces the standard double mark-up effect (cf. Spengler, 1950).

As defined above, the absorption costing is closely related to the transfer pricing or the separation rules: the specific ingredient of the absorption costing is the capacity constraint which plays the role of a vertical restraint. Accordingly the impact of the absorption costing in terms of profits, prices and quantities is likely to resort to standard arguments drawn from the vertical restraint literature (cf. Rey and Tirole, 1986). Furthermore, the separation and the transfer pricing rules are natural benchmarks of absorption costing, more legitimate than the marginal cost pricing (embedded here in the vertical integration) with regard to the current organization forms in business where the vertical integration is not necessarily allowed for the sake of flexibility or exogenous managerial considerations.

The paper is aimed at developing a comparative analysis of these vertical relations in the Cournot oligopoly case. The rest of the paper is organized as follows. The next section provides a short review of the related literature. Section (3) is devoted to the principal-agent formulation of the absorption costing rule; we prove that, under absorption costing, two different policies are likely to be alternatively used by the firm: (i) The full-cost pricing policy, where the capacity is equal to the output; this policy is used for low values of the fixed cost. (ii) the partial cost pricing policy where the capacity is strictly higher than the output; only a part of the fixed cost is passed on the downstream unit; it coincides to the transfer pricing or the separation rule according to the payoff function assigned to the upstream unit.

The Cournot oligopoly case is analyzed in section 4 . Two types of informational structures are considered according to whether the downstream unit of any firm observes the capacities of the rivals (referred to as open loop and closed loop equilibrium in the dynamic games literature) . They yield different results in the separation and the transfer pricing cases since it implies a narrower competition between the downstream units. Either in closed loop or in open loop, for intermediate values of the fixed cost, the absorption costing leads to a coexistence of a full-cost and a partial cost pricing equilibrium. Section (5) is devoted to a systematic profit comparison of the various pricing rules. Except in the monopoly case, there exists a wide range of values of the fixed cost where the full-cost pricing dominates all the other rules. In addition, there exists a specific value of the fixed cost for which the full-cost pricing duplicates the monopoly and then leads to the first best solution of the Cournot oligopoly. Concluding remarks are given in section (6).

\footnotetext{
${ }^{1}$ We do not consider here two-part tariff pricing rules, assuming for instance that resale opportunities cannot be prevented at the downstream level.
} 


\section{Related literature}

Hence the recent literature has advocated the strategic content of the absorption costing practices: What actually matters is the type of cost reporting and internal accounting practices used by the organization and its impact on the performance of the firms according to the strategic interactions at work in the competitive environment: Alles \& Datar (1998) use a two-tier structure of the firm; they develop a model where two oligopolistic decentralized firms strategically select their cost-based transfer prices between production and marketing departments. They show how a cost-based transfer price can be used as a competitive weapon through a cross subsidization of some products. Other contributions in this vein include Narayanan (2000) and Hughes and Kao (1998).

Our contribution is in the line of Göx (2000) who analyses the use of the transfer pricing as a strategic device in divizionalized firms operating on a price setting differentiated duopoly. This author shows that the adoption of an absorption costing rule is perceived by any firm as signalling that the opponent uses transfer prices above marginal cost and then is a source of higher profits for both duopolists; Göx introduces the absorption costing without stressing the fact that its existence conditions are not satisfied for high values of the fixed cost. In addition the separation case is not considered by this author although it should not be dominated by the transfer pricing in a price setting duopoly.

Our contribution deals with Cournot oligopoly competition which allows us to analyze the sensitivity of the results with respect to the industry concentration (measured by the number of oligopolists). In this quantity setting context, the transfer pricing rule is dominated by all the other rules. The separation case deserves a particular attention as it coincides with the absorption costing rule for high values of the fixed cost. The separation is compared with the integration as in Greenhut and Ohta (1979), Lin, (1988), Bonanno and Vickers, (1988) and similar results are found.

\section{A principal-agent formulation of absorption costing}

We consider here a two-tier firm where the upstream unit is in charge of providing a capacity of service or product $y$ to the downstream unit which operates on a monoproduct market. The upstream unit incurs a fixed cost $F$ which covers the infrastructure expenditures and the overhead associated with the delivery of capacity $y$. The downstream unit sells a quantity $q$ on the final market at price $p$. Two assumptions are made with regard to the capacity management to justify the fact that capacity $y$ is explicitly considered only in the absorption costing case in which it plays the role of a cost driver.

Assumption 1: the upstream unit is is contractually committed to provide the downstream unit with a feasible level of capacity.

Under this assumption, the capacity constraint $q \leq y$ cannot be used as a strategic device, for instance like in Kreps and Scheinkman's duopoly model (1983). Here the downstream unit makes his decision without taking care of the capacity constraint which is managed by the upstream unit. If the capacity constraint is not fulfilled, the vertical relationship is broken with some penalties to both parties. Hence the capacity constraint can be seen as the participation con- 


\begin{tabular}{|l|l|l|l|l|}
\hline & Integration & $\begin{array}{c}\text { Transfer } \\
\text { pricing }\end{array}$ & $\begin{array}{c}\text { Absorption } \\
\text { costing }\end{array}$ & Separation \\
\hline $\begin{array}{c}\text { upstream } \\
\text { decision variables }\end{array}$ & $q$ & $w$ & $y(\geq q)$ & $w$ \\
\hline upstream profit & $p q-F$ & $p q-F$ & $\left(\frac{F}{y}\right) q-F$ & $w q-F$ \\
\hline $\begin{array}{l}\text { downstream } \\
\text { decision variable }\end{array}$ & $\emptyset$ & $q$ & $q$ & $q$ \\
\hline downstream profit & $\emptyset$ & $(p-w) q$ & $\left(p-\frac{F}{y}\right) q$. & $(p-w) q$ \\
\hline
\end{tabular}

Table 1: The pricing rules

straint imposed by the downstream unit, which intervenes only in the upstream firm's program.

Assumption 2: the variable cost of capacity is negligible.

This assumption is quite realistic in network systems, where the great part of the capacity costs are fixed ( for instance transporting networks like railways, computer networks etc...). .Hence the production capacity essentially plays the role of a budgeted quantity level with no specific variable cost incurred. This assumptions - which could be relaxed in further investigations - yields more tractable results and easier comparisons. In addition, for the sake of simplicity, we assume that the variable production costs are zero. This later assumption does not change the results, as it is well known in IO literature. The absorption costing rule can be defined in a principal-agent setting as follows (with the output quantity as decision variable of the downstream unit):

Definition 2 (Absorption costing) The upstream unit fixes the production capacity $y \geq q$. and uses it by charging the downstream unit with a cost per unit of output $F / y$. She exerts its monopoly power via this cost passing so as to maximize her profit $U=F(q / y-1)$. The downstream unit uses $F / y$ as a cost parameter in maximizing his profit $D=(p-F / y) q$, under the prevailing final market conditions.

In this definition the upstream firm seeks to minimize the part of the fixed cost which is not passed on the downstream unit through the average capacity cost. The upstream unit program can be written as the principal problem (1), where the constraints $q=\arg \max D$ and $y-q \geq 0$. are respectively the incentive compatibility and the participation constraint of the agency game.

$$
\left\{\begin{array}{l}
\max _{y, q} U \\
q=\arg \max D \\
y-q \geq 0 .
\end{array}\right.
$$

Under this principal-agent formulation, the absorption costing rule can be compared with the separation, the pricing transfer and the separation rules, as summarized in table (1). Thanks to assumptions 1 and 2, production capacity is always equal to the output under these pricing rules and can be dropped out.

Such a panorama indicates how the absorption costing is conceptually close to the separation rule: Using the change of variable $w=F / y$ program (1) can be rewritten as follows: 


$$
\left\{\begin{array}{l}
\max _{q, \omega}(w q-F) \\
q=\arg \max (p-w) q \\
w \leq F / q
\end{array}\right.
$$

Hence absorption costing is nothing else than a separation rule when the principal operates on a feasible subset. When the capacity constraint $w \leq F / q$ is not binding, the absorption costing coincides with the separation. This guarantees the existence of this concept for any value of the fixed cost. In addition the capacity constraint can be seen as an upstream vertical restraint, something like a wholesale maintenance price, expressing that the upstream unit cannot recover more than the fixed cost. Then the absorption costing lies somewhere between the transfer pricing and the separation structures. This intermediate position has some strategic features which deserve consideration in competitive contexts.

\section{Cournot competition}

Let us consider the situation of $n$ identical firms involved in Cournot competition on quantities $q_{i}, i=1, \ldots, n$ sold at the downstream level, on a final market determined by the inverse demand function $p(q)$, with $q=\sum_{i=1}^{n} q_{i}$. We assume than $p^{\prime}<0, p^{\prime \prime} \leq 0$. Each firm faces a fixed cost $F$. The net (of fixed cost) industry profit is $p q-n F$ and the gross industry profit is $p q$.

Clearly, in the integration case, the standard Cournot equilibrium is found, with a global quantity $q^{v}=\sum_{i=1}^{n} q_{i}^{v}$ solution of $p+p^{\prime} q / n=0$.

The other pricing rules deal with a two-stage game setting: At stage 1, the upstream units simultaneously fix the $y_{i}$ or $w_{i}$; at stage 2 , the downstream units are involved in a Cournot competition on the quantities $q_{i}$. Two types of information structures are commonly introduced in such dynamic games ${ }^{2}$ :

- The open loop game in which, at the beginning of stage 2 , the downstream unit of any firm $i$ does not observe the decisions taken at stage 1 by his rivals.

- The closed loop game in which, at the beginning of stage 2 , the downstream unit of any firm $i$ observes the decisions taken at stage 1 by his rivals .

\subsection{The open loop absorption costing case}

In the open loop case, the downstream unit $i$ determines the quantity sold $q_{i}$ for any values of the quantities sold by the rivals, $q_{j}, j \neq i$. and the capacity held by the upstream unit $i, y_{i}$.

The first order maximization of the downstream unit $i$ yields the relation:

$$
\left(p\left(q_{-i}+q_{i}\right)-\frac{F}{y_{i}}\right)+p^{\prime}\left(q_{-i}+q_{i}\right) q_{i}=0,
$$

\footnotetext{
${ }^{2}$ Göx (2000) refers to both situations as unobservable and observable games.
} 
where $q_{-i}=\sum_{j \neq i} q_{j}$. Accordingly, the upstream unit maximization program is:

$$
\left\{\begin{array}{l}
\min _{q_{i}, y_{i}} F\left(1-q_{i} / y_{i}\right) \\
q_{i} \leq y_{i} \\
\left(p\left(q_{-i}+q_{i}\right)-\frac{F}{y_{i}}\right)+p^{\prime}\left(q_{-i}+q_{i}\right) q_{i}=0
\end{array}\right.
$$

the solution of which defines the reaction function $y_{i}\left(q_{-i}\right), q_{i}\left(q_{-i}\right)$, respectively of the production capacity and output of firm $i$. Since the firms are identical, we restrict the analysis to symmetric solutions. Let us denote $\left\{q_{i}^{*}(F), y_{i}^{*}(F)\right\}, i=$ $1, \ldots, n$; the open loop equilibrium output and capacity of any firm for a given value of the fixed cost $F$ incurred by any firm. They are determined by the following proposition:

Proposition 3 (Absorption costing ) There exist two fixed cost values, $\hat{F} \geq$ $F^{s}>0$, so that, for any firm $i$ :

- For $F \leq F^{s}$, all the firms use a full-cost pricing policy; the unique equilibrium is such that:

- Output function $q_{i}^{*}(F)=q^{*}(F) / n$ is differentiable and strictly decreasing, on $[0, \hat{F}]$, with $q^{*}(F)$ the solution of:

$$
p+n F / q+p^{\prime} q / n=0,
$$

so that $q^{*}(0)=q^{v}$.

- No excess capacity occurs i.e. $y_{i}^{*}(F)=q^{*}(F) / n$, and the fixed cost is fully passed on.

- For $F>\hat{F}$ : all the firms use a partial cost pricing policy; the unique equilibrium is such that:

- The output function $q_{i}^{*}($.$) , is constant and equal to the separation$ output $q_{i}^{s}=q^{s} / n$ with $q^{s}$ solution of

$$
p+p^{\prime \prime} q^{2} / n^{2}+3 p^{\prime} q / n=0 .
$$

- Excess capacity occurs, i.e. $q^{s} / n<y_{i}^{*}(F)$ and the fixed cost is partially passed on.

- The production capacity $y_{i}^{*}($.$) is a linear and increasing function.$

- For $F^{s} \leq F \leq \hat{F}$, all the firms use either a full or a partial cost pricing policy; the two types of equilibria coexist.

Proof. see Appendix

This proposition characterize the absorption costing equilibrium. When the fixed cost is low $\left(F \leq F^{s}\right)$, all the firm use the full-cost pricing policy. The fixed cost is fully passed on the downstream units through an average cost computed on the basis of the quantity really sold according to the competition conditions arising on the final market. This case coincides with the absorption costing 
notion used by Göx (equation (25) p. 339) in a price setting duopoly context. When the fixed cost is high $(\hat{F} \leq F)$, all the firms use the separation rule, where only a part of the fixed cost is passed on the downstream units. When the fixed cost takes intermediate values $\left(F^{s} \leq F \leq \hat{F}\right)$, the two previous types of equilibria coexist. Such coexistence is inherent to the oligopoly competition, since, in the monopoly case, $F^{s}=\hat{F}$.

In the linear case, the threshold values of the fixed cost are $\hat{F}=\frac{a}{4(n+1)} \geq$ $F^{s}=\frac{2 a}{(n+3)^{2}}$. The full-cost industry output and the market price are given by $q^{f}=\frac{n\left(a+\sqrt{\left(a^{2}-4 F(n+1) a\right)}\right)}{2 a(n+1)}$ and $p^{f}=\frac{a(n+2)-n \sqrt{\left(a^{2}-4 F(n+1) a\right)}}{2(n+1)}$. In the separation/full-cost pricing case, we have $q^{s}=\frac{n}{(n+3)}, y_{i}^{s}=\frac{1}{2} F \frac{n+3}{a}$, $p^{s}=\frac{3 a}{n+3}$.

\subsection{The closed loop absorption costing case}

In the closed loop setting, the downstream unit of each firm observes the production capacity levels of all the firms. At stage 1 the upstream unit of firm $i$ takes into account the absorption costing policy used by her rivals so that she has to solve the following optimization program:

$$
\left\{\begin{array}{l}
\min _{q_{j}, y_{i}} F_{i}\left(1-q_{i} / y_{i}\right) \\
y_{i} \geq q_{i} \\
\left(p(q)-\frac{F}{y_{j}}\right)+p^{\prime}(q) q_{j}=0 \\
j=1, \ldots, n
\end{array}\right.
$$

Proposition 4 Proposition (3) holds in the closed loop case, with a partial cost pricing quantity $q^{s c}$ solution of:

$$
q\left(-p n+p n^{2}-p^{\prime} q+2 p^{\prime} n q\right) p^{\prime \prime}+p^{\prime} n\left(p n^{2}+2 q p^{\prime} n+q p^{\prime}\right)=0 .
$$

Proof. see Appendix.

This proposition implies that the open loop and closed loop equilibria differ under the separation rule; but there is no difference when the full-cost pricing policy holds, since relation (4) is valid in both case and then yields the same quantity. As a result the threshold value of the fixed cost, $F^{s c}$, at which the closed loop absorption costing rule switches to the separation differs from $F^{s}$. In the linear case, we have $F^{s c}=\frac{n a}{(n+1)^{3}}$, and $q^{s c}=\frac{n^{2}}{(n+1)^{2}}, y_{i}^{s c}=F \frac{1+n}{a}$, $p^{s c}=\frac{a(2 n+1)}{(n+1)^{2}}$. 


\subsection{The closed loop transfer pricing game}

In the open loop case, the transfer pricing still coincides with the vertical integration, as in the monopoly. This is no longer true in the closed loop game, for $n>1$. In this case, , the optimization program of the upstream unit $i$ is

$$
\left\{\begin{array}{l}
\max _{w_{i}, q_{j}} p(q) q_{i} \\
\left(p(q)-w_{j}\right)+p^{\prime}(q) q_{j}=0, \\
j=1, \ldots, n
\end{array}\right.
$$

Proposition 5 The closed loop transfer pricing game is defined by a quantity $q^{t}$ solution of the equation

$$
\left(p n+p^{\prime} q / n\right) p^{\prime}+p^{\prime \prime} p(n-1) q / n=0 .
$$

Proof. see Appendix.

In the linear case, we get $q^{t}=\frac{1}{n^{2}+1} n^{2}$ and $p^{t}=\frac{a}{n^{2}+1}$ :

\section{Comparisons of profits}

We are going to compare the various rules in the Cournot oligopoly context. Since the partial cost pricing coincides with the separation both in the open loop and closed loop cases, only the full-cost pricing policy will be considered in this section.

\subsection{Dominance relations}

Clearly the comparisons can be made in terms of industry gross profit $P(q)=$ $p(q) q$, since the firms are identical. Under the assumptions made $P$ is a concave function, such that:

$$
P^{\prime}(q) \geq 0 \text { for } q \leq q^{m} \text {, and } P^{\prime}(q) \leq 0 \text { for } q \geq q^{m},
$$

where $q^{m}$ is the monopoly quantity, solution of $p+p^{\prime} q=0$. Let $\pi=p+p^{\prime} q / n$, the marginal profit of any oligopolist. Since $\pi$ is a decreasing function, we have:

$$
\pi(q) \geq 0 \text { for } q \leq q^{v} \text {, and } \pi(q) \leq 0 \text { for } q \geq q^{v} .
$$

Clearly $\pi\left(q^{m}\right)=p(1-1 / n) \geq 0$, then $q^{m} \leq q^{v}$ and, of course, $P\left(q^{m}\right) \geq P\left(q^{v}\right)$. Properties (10) and (11) determine all the dominance relations we are going to establish now.

Proposition 6 The vertical integration dominates the closed loop transfer

Proof. Using $(9), \pi\left(q^{t}\right)=-p^{\prime \prime} p(n-1) q /\left(n p^{\prime}\right)-(n-1) p$ which is negative under the assumptions made, then according to (11), $q^{v} \leq q^{t}$ and, since $q^{m} \leq q^{v}$, the output value $q^{t}$ lies in the interval where $P^{\prime} \leq 0$. As a result, $P\left(q^{v}\right) \geq$ $P\left(q^{t}\right), \forall n$.

This proposition contradicts some results of Alles and Datar (1998) or Göx (2000). These authors find the opposite relation in a differentiated price duopoly. 
These diverging results can be explained in terms of strategic complementarity/substitutability which contrasts the price and the quantity setting competition $^{3}$. This suggests that the type of competition holding at the final market level (price vs quantity setting) matters.

Proposition 7 There exists $n^{s} \geq 3$, such that, for $n \geq n^{s}$, the open loop separation dominates the integration.

This proposition is in line with the literature on vertical integration in oligopoly (e.g. Greenhut and Ohta, 1979, Lin, 1988, Bonanno and Vickers, 1988, Abiru et al., 1998, Cavero et al. 1998) ). Under the assumptions made here, vertical separation induces a "dampening of the competition" between the firms at the upstream level, so that the profits are better off under vertical separation, both in the closed loop and open loop case, contrary to the monopoly case, where the double markup effect dissipates the profit. This argument is still valid for the full-cost pricing which operates in a similar way as the separation does

Proof. see appendix

Proposition 8 : There exists $n^{s c} \geq 2$, such that, for $n \geq n^{s c}$, the open loop separation dominates the closed loop.

Observability reinforces the competition pressure since it makes any upstream unit aware of the impact of the rival's downstream decisions. Then the profit is lower under observability for market structures less concentrated than the duopoly.

Let us now formulate the main result of this paper which is given by the following lemma and theorem.

Lemma 9 There exists a value $F^{m}=(n-1) P^{m} / n^{2} \in[0, \hat{F}]$ at which the full-cost pricing oligopoly duplicates the standard monopoly.

Proof. see Appendix.

Theorem 10 For $n \geq 2$, there exists an interval of fixed cost values $\left[F^{-}, F^{+}\right] \subset$ $[0, \hat{F}]$, where the full-cost pricing rule dominates the separation and then all the pricing rules.

Proof. The theorem is an immediate consequence of the lemma (9). For $F=F^{m}$, the full-cost pricing strictly dominates all the other pricing rules. By continuity of the profit function, this is still true in a neighborhood $\left[F^{-}, F^{+}\right]$of $F^{m}$,except in the monopoly case where $F^{m}=0$.

Since the full-cost pricing dominates all the other pricing rules for a set of values of the fixed cost around $F^{m}$, the absorption costing rule given by definition (2) is dominant for any value of the fixed cost, except in a neighborhood of 0 and, eventually, of $\hat{F}$.

\footnotetext{
${ }^{3}$ The transfer pricing has not to be recommanded in competitive contexts, since it tends to exacerbate the strategic interactions at the downstream level : for instance, it can be checked that, in standard Hotelling model, the transfer pricing rule is dominated by the separation, which is therefore a better challenger of the absorption costing rule.
} 
Proposition 11 There exists $\hat{n} \geq 2$, such that, for any $F \in[0, \hat{F}]$ and $n \geq \hat{n}$, the full-cost pricing dominates the integration.

Proof. see Appendix.

This proposition states that dominance of the absorption costing is stronger vis à vis the integration rule since it holds for any value of the fixed cost.

\subsection{Interpretations and comments}

According to these results three case have to be considered:

(i) In the monopoly case $(n=1)$, we have $F^{m}=0, F^{s}=F^{s c}=\hat{F}$. The situation is represented on figure (1). Clearly, the integration dominates all the other pricing rules. More interestingly, the full-cost pricing policy dominates the separation rule. This confirms the role of vertical restraint played by the capacity constraint which dampens the double mark-up effect between the upstream and the downstream unit and then restore a part of the profit which would have been gained under the integration rule.

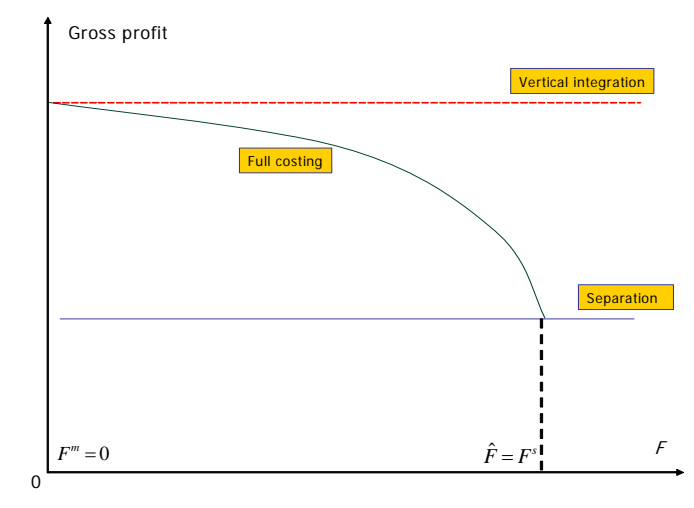

Figure 1:

(ii) In a highly concentrated oligopoly, i.e for intermediate values of $n$ (i.e. $\leq$ 3 ), we have the situation depicted on figure (2), with $0<F^{m}<F^{s}<F^{s c}<\hat{F}$; The closed loop separation dominates the open loop which in turn dominates the integration. Both of them dominates the full-cost pricing in two extreme cases: (i) when $F$ is close to zero, the "dampening of competition" effect prevails (ii) when $F$ is higher and close to $\hat{F}$, the double markup effect deteriorates the full-cost pricing profit; this happens in the coexistence area. In-between, these two effects are neutralized by the vertical restraint mechanism and the full-cost pricing is better off.

(iii) In a weakly concentrated oligopoly case, namely for high values of $n$, the situation is represented on figure (3), with $F^{m}>0, F^{s c}<F^{s}<F^{m}<$ $\hat{F}$. The open loop dominates the closed loop which dominates in turn the vertical integration. When the fixed cost is low $\left(F \leq F^{s}\right)$, the full-cost pricing is close to the integration case, it is dominated by the separation. When the fixed cost takes higher values $\left(F>F^{s}\right)$, the vertical restraint effect is stronger so that the 


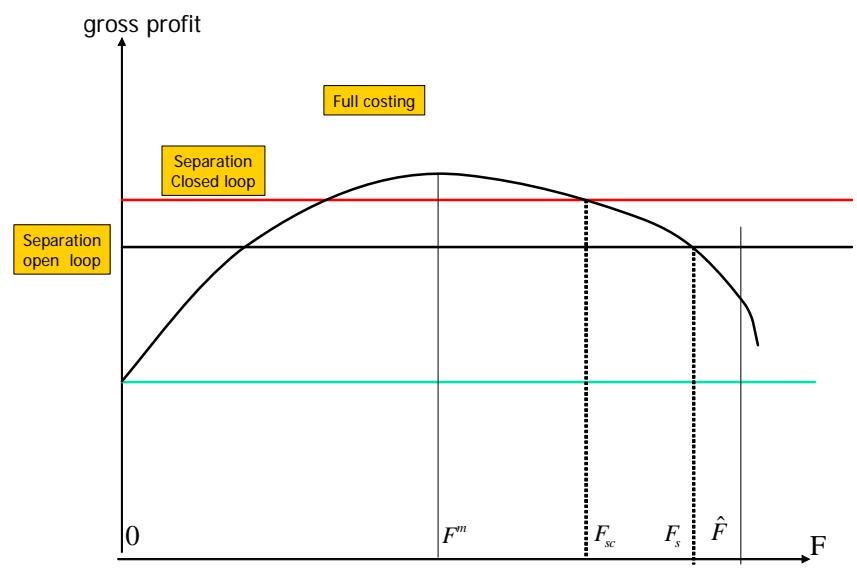

Figure 2:

full-cost pricing dominates the separation. This occurs in the coexistence area for values of $F$ namely where there are two absorption costing equilibria.

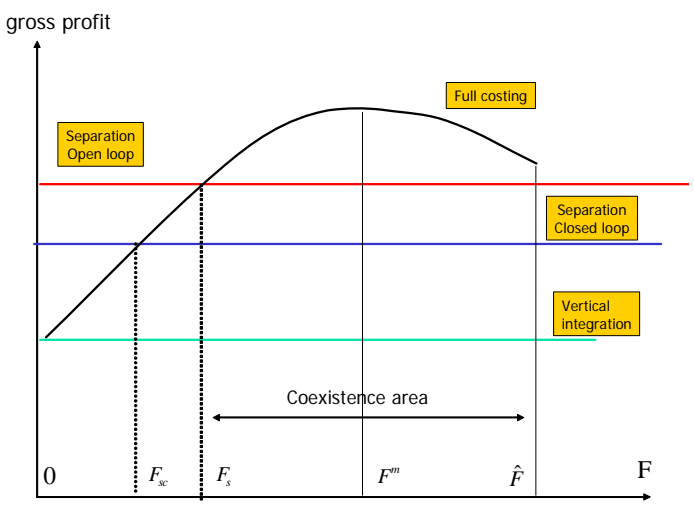

Figure 3:

A meaningful property immediately results from lemma (9): the firms would benefit to use the full-cost pricing by charging the same level $\hat{F}$ of fixed cost which ensures the best possible profit value $P^{m} / n$ to each of them. One may consider that computing the fixed cost level resorts to a strategic choice made by the top management to be transmitted to the upstream unit and then passed on the downstream unit. Our result suggest that the fixed cost determination can be used as a coordinating device among competing firms, with the assistance of an eventual common provider of the technology used in the industry. 


\section{Conclusion}

The optimality of the full-cost pricing indicated in the title of this paper turns out to have a threefold meaning: (i) The full-cost pricing derives from an optimization program based on a principal-agent formulation of the organization (section 3). (ii) In a Cournot competition setting, it may dominates all other pricing rules and (iii) for a specific value of the fixed cost, it duplicates the monopoly and then leads to a first best solution of the Cournot oligopoly (section 5). The key ingredient of our analysis is to consider the firm as a two tier organization involved in a principal-agent relationship. Such a decomposition have some relevancy with regard to the common business practices: in many industries, the firms have an upstream unit working as the control entity of downstream units, while using the production capacity as a relevant cost driver for the accounting management, and then a proxy measure of the budgeted output.

Extensions of this work have to consider the role of the production capacity in a more general way. When the variable capacity cost is non zero, full-cost pricing policy does not change and then all the dominance properties established here are valid. although the partial cost pricing no longer coincides with the separation structure. Relaxing the zero capacity cost assumption does not alters substantially our main findings. More importantly, a particular attention should be given to oligopoly models which explicitly introduce the production capacities (cf. Thépot, 1995, for Bertrand competition); the question is to see what is going on when the production capacity is borne by the downstream units as do Kreps and Scheinkman (1983) in a price setting oligopoly context. Exploring other forms of competition, market structures and product differentiation is on our research agenda; as it is well documented in the literature on vertical relations, these elements crucially determine the comparative results in terms of performance and stability. More generally, our approach turns out to be a rather simple way of incorporating increasing returns to scale elements in IO standard models, in the perspective of examining technology choice or strategic investment problems, for instance.

\section{References}

[1] Abiru,M., B. Nahata, S. Raychaudhuri, M. Waterson, 1998, Equilibrium structures in vertical oligopoly, Journal of Economic Behavior and Organization, 37, 463-480.

[2] Alles, M. \& Datar, 1998, Strategic transfer pricing, Management Science, $44, \mathrm{n}^{\circ} 4,451-461$

[3] Balakrishnan, R. \& Sivaramakrishnan, K. 2002, A critical overview of the use of full-cost data for planning and pricing, Journal of Management Accounting Research,14, 3-31.

[4] Bonanno, G., J. Vickers, 1988, Vertical separation, Journal of Industrial Economics, 36, 257-263. 
[5] Cavero, S., Cebollada, J., Salas, V. 1998, Price formation in channels of distribution with differentiated products. Theory and empirical evidence., International Journal of Research in Marketing, 15, 427-441

[6] Corbett, C., and U. Karmarkar, 2001, Competition and structure in serial supply chains with deterministic demand, Management Science, 47, $n^{\circ} 7,966-978$.

[7] Choi S.C. ,1996, Price competition in a duopoly common retailer channel, Journal of Retailing, 72(2) 117-134.

[8] Göx, R., 2000, Strategic transfer pricing, absorption costing and observability, Management Accounting Research, 11, 327-348.

[9] Govindaradjan, V. and R.N. Anthony, 1983, How to use cost data on pricing decisions, Management Accounting Research, 30-37

[10] Greenhut, M. and H. Ohta, 1979, Vertical integration of successive oligopolists, 69, 137-141.

[11] Hall, R. et C. Hitch, 1939, Price theory and business behavior, Oxford Economic Papers, 2: 12-45.

[12] Hanson, W., 1992, The dynamics of cost-plus pricing, Managerial and Decision Economics, 13: 149-161.

[13] Hughes, J. and J.L. Kao, 1998, Cross subsidization, cost allocation and tacit coordination, Review of Accounting Studies, 2, 265293.

[14] Kaplan, R.S. and A. Atkinson, 1998, Advanced Management Accounting, Prentice Hall, Englewood Cliffs, 3nd edition

[15] Kreps, D. and J. Scheinkman, 1983, Quantity precommitment and Bertrand competition yield Cournot outcomes, Bell Journal of Economics, 14, 326-337.

[16] Laffont, J.J., P. Rey and J. Tirole, 1998a, Network competition, I: overview and non discriminatory pricing, RAND Journal of Economics, 29, n¹,1-37.

[17] Laffont, J.J., P. Rey and J. Tirole, 1998b, Network competition, II: price discrimination, RAND Journal of Economics, 29, $\mathrm{n}^{\circ} 1,38-.56$.

[18] Lin, J.Y. 1988, Oligopoly and vertical integration, American Economic Review, 78, 251-254.

[19] Lukas, M. 1999, The pricing decision: economists versus accountants, Management Accounting, 34-35

[20] McGuire \& R. Staelin, (1983), An industry equilibrium analysis of downstream vertical integration, Marketing Science, 2 n$^{\circ} 2,161-191$

[21] Mongin, P., 1997, The marginalist controversy, Handbook of Economic Methodology, J. Davis, W . Hands et U. Maki, eds. Edward Elgar, 558562 . 
[22] Narayanan, V.and M. Smith, 2000, Impact of competition and taxes on responsibility center organization and transfer prices, Contemporary Accounting Research, 17 n³,497-529.

[23] Roberts, J., 2004, The Modern Firm, Oxford University Press

[24] Spengler, J.J., 1950, Vertical Integration and Antitrust Policy, Journal of Political Economy, 58, 347-352.

[25] Rey, P. and J. Tirole, 1986, The logic of vertical restraints, American Economic Review, 76, 921-940.

[26] Thépot J., 1995, Bertrand oligopoly with decreasing returns to scale, Journal of Mathematical Economics, 24, 689-718.

[27] Zhao, L. 2000, Decentralization and transfer pricing under oligopoly, Southern Economic Journal, 67(2), 414-426.99

Proof of proposition (3).

The first order conditions of programs (3) are:

$$
\left\{\begin{array}{l}
\left(F / y_{i}\right)-\alpha_{i}+\lambda_{i}\left(2 p^{\prime}+p " q_{i}\right)=0 \\
-F \frac{q_{i}}{y_{i}^{2}}+\alpha_{i}+\lambda_{i} F / y_{i}^{2}=0 \\
\alpha_{i} \geq 0, \alpha_{i}\left(y_{i}-q_{i}\right)=0 .
\end{array}\right.
$$

From relations (12), we know that no excess capacity holds when $\alpha_{i}>0$, namely $\lambda_{i}=0, \alpha_{i}=\frac{F}{y_{i}}$ and $q_{i}=y_{i}$.

$$
\gamma(q, F)=\left(p(q)-\frac{n F}{q}\right)+p^{\prime}(q) q / n
$$

We have $\gamma\left(q^{v}, 0\right)=0$ and $\frac{\partial \gamma}{\partial q}\left(q^{v}, 0\right)<0$. Using the implicit functions theorem, there exist two intervals $\left[0, \hat{F}\left[\right.\right.$ and $\left[\hat{q}, q^{v}[\right.$ and a unique continuous function $q^{*}:\left[0, \hat{F}[\rightarrow] \hat{q}, q^{v}\right]$, such that $q^{*}(0)=q^{v}$ and $\gamma\left(q^{*}(F), F\right)=0, \forall F \in[0, \hat{F}[$. The highest possible $\hat{F}$ can be defined as the (lowest) value of $F$ such that $\frac{\partial \gamma}{\partial q}\left(q^{*}(F), F\right)=0$ (which exists by continuity of $\left.\frac{\partial \gamma}{\partial q}\right)$. Hence $\hat{q}=q^{*}(\hat{F})$ satisfies the relation $\left(1+\frac{1}{n}\right) p^{\prime}+n F / q^{2}+p^{\prime \prime} q / n=0$. Eliminating $F$ thanks to relation $\gamma(q, F)=0$ yields $\hat{q}$, solution of:

$$
f(q)=p+\left(1+\frac{2}{n}\right) p^{\prime} q+p^{\prime \prime} q^{2} / n=0 .
$$

Furthermore, $\frac{d q^{*}}{d F}=-\frac{\partial \gamma}{\partial F} / \frac{\partial \gamma}{\partial q} \leq 0$, for $F \in\left[0, \hat{F}\left[\right.\right.$. The function $q^{*}$ is decreasing and the equilibrium output quantity $q^{*}(F)$ is lower than $q^{v}$.

Excess capacity occurs for $\alpha_{i}=0$, namely when $\lambda_{i}=q_{i}$. Relations 12 gives $q=q^{s}$,the separation case solution, defined by:

$$
h(q)=p+p^{\prime \prime} q^{2} / n^{2}+3 p^{\prime} q / n=0 .
$$


relation $\left(p-\frac{F}{y_{i}}\right)+p^{\prime} q / n=0$ yields the capacity level proportional to the fixed cost $F, y_{i}=F /\left(p\left(q^{s}\right)+p^{\prime}\left(q^{s}\right) q^{s} / n\right)$. Consequently, the capacity constraint is satisfied for any values of $F$ such that $y_{i} \geq q^{s} / n$, namely $\gamma\left(q^{s}, F\right) \leq 0$, i.e. for $F \geq F^{s}=q^{s}\left(p\left(q^{s}\right)+p^{\prime}\left(q^{s}\right) q^{s} / n\right) / n$.

We have $f(0)=h(0)=p(0)$ and, under the assumptions made on the inverse demand function, $f^{\prime} \leq 0$ and $h^{\prime} \leq 0$. Let us consider the function $k=f-g=$ $q(n-1) \frac{n p^{\prime}+p^{\prime \prime} q}{n^{2}}$. Function $k$ is decreasing with $k(0)=0$, so that $k(q) \leq 0, \forall q$. In particular, $k(\hat{q}) \leq 0$. This implies $h(\hat{q}) \geq 0=h\left(q^{s}\right)$; then, as function $h$ is decreasing, $\hat{q} \leq q^{s}$. Since function $q^{*}(F)$ is decreasing, this implies

$$
F^{s} \leq \hat{F} .
$$

Hence, for values of the fixed cost in interval $\left[F^{s}, \hat{F}\right]$, there is two Nash symmetric equilibria. Such a multiplicity disappears for $n=1$, where $k \equiv 0$ and $F^{s}=\hat{F}$

It can be checked that the first order conditions are also sufficient: in the full-cost pricing case, the objective function of the upstream unit is zero, it cannot be higher in the feasible set; in the full-cost pricing case, we are in the standard separation problem. Hence the result.

\section{Proof of proposition (4)}

Clearly, there is no difference with the open loop when the full-cost pricing policy holds. In the full-cost pricing case, the first order conditions of program (6) are:

$$
\left\{\begin{array}{l}
\left(F / y_{i}\right)+\lambda_{i i}\left(2 p^{\prime}+p^{\prime \prime} q_{i}\right)+\sum_{i \neq j} \lambda_{i j}\left(p^{\prime}+p^{\prime \prime} q_{j}\right)=0, \\
\lambda_{i j}\left(2 p^{\prime}+p^{\prime \prime} q_{j}\right)+\sum_{k \neq j} \lambda_{i k}\left(p^{\prime}+p^{\prime \prime} q_{k}\right)=0, j \neq i \\
\lambda_{i i}=q_{i}
\end{array}\right.
$$

In the symmetric case, the multiplier $\lambda_{i j}=\mu$,for $j \neq i$ is the same for all pairs of firms. Then (16) yields

$$
\left\{\begin{array}{l}
p+(q / n)\left(3 p^{\prime}+p^{\prime \prime} q / n\right)+(n-1) \mu\left(p^{\prime}+p " q / n\right)=0 \\
\mu\left(2 p^{\prime}+p^{\prime \prime} q / n\right)+(q / n)\left(p^{\prime}+p^{\prime \prime} q / n\right)+\mu(n-2)\left(p^{\prime}+p " q / n\right)=0
\end{array}\right.
$$

Eliminating $\mu$ results in the relation: $q\left[p\left(n^{2}-1\right)+p^{\prime} q(2 n-1)\right] p^{\prime \prime}+p^{\prime} n\left[p n^{2}+p^{\prime} q(2 n+1)\right]=$ 0 . Hence the result.

\section{Proof of proposition(5).}

The first order conditions are:

$$
\left\{\begin{array}{l}
p+p^{\prime} q_{i}+\lambda_{i i}\left(2 p^{\prime}+p^{\prime \prime} q_{i}\right)+\sum_{i \neq j} \lambda_{i j}\left(p^{\prime}+p^{\prime \prime} q_{j}\right)=0, \\
p^{\prime} q_{i}+\lambda_{i j}\left(2 p^{\prime}+p^{\prime \prime} q_{j}\right)+\sum_{k \neq j} \lambda_{i k}\left(p^{\prime}+p^{\prime \prime} q_{k}\right)=0, j \neq i \\
\lambda_{i i}=0
\end{array}\right.
$$

In the symmetric case, the multiplier $\lambda_{i j}=\mu$,for $j \neq i$ is the same for all pairs of firms. Then (18) yields:

$$
\left\{\begin{array}{l}
p+(q / n) p^{\prime}+(n-1) \mu\left(p^{\prime}+p^{\prime \prime} q / n\right)=0 \\
p^{\prime}(q / n)+\mu\left(2 p^{\prime}+p^{\prime \prime} q / n\right)+\mu(n-2)\left(p^{\prime}+p^{\prime \prime} q / n\right)=0
\end{array}\right.
$$


or, after eliminating $\mu$ : we have $\left(p+p^{\prime} q / n\right) p^{\prime}+(n-1) p\left(p^{\prime}+p^{\prime \prime} q / n\right)$, hence the result.

\section{Proof of proposition (7).}

Let us compute $\pi\left(q^{s}\right)$. Thanks to relation (11), we have $\pi\left(q^{s}\right)=\left[2 p-p^{\prime \prime} q^{2} / n\right] / 3 \geq$ 0 ,i.e. $q^{s} \leq q^{v}$. Similarly, we have $P^{\prime}\left(q^{s}\right)=\left[(3-n) p-p^{\prime \prime} q^{2} / n\right] / 3$. Then, there exists $n^{s} \geq 3$, such that, for $n \geq n^{s}, P^{\prime}\left(q^{s}\right) \leq 0$, namely $q^{s} \geq q^{m}$, and then $P\left(q^{s}\right) \geq P\left(q^{v}\right)$.Hence the result.

Proof of proposition (8).

Output quantity $q^{s c}$ is defined by relation (7). Let us consider function $h$ defined as in (15), so that $h\left(q^{s}\right)=0$. Clearly, $q \lesseqgtr q^{s} \Leftrightarrow h(q) \gtreqless 0$. Straightforward computations yield $h\left(q^{s c}\right)=-\frac{(n-1)\left(p n+2 p^{\prime} q\right)\left(p^{\prime} n+q p^{\prime \prime}\right)}{n^{2} p^{\prime}}$, which is negative for $n \geq n^{s c}=-2 p^{\prime}\left(q^{s c}\right) q^{s c} / p\left(q^{s c)}\right.$. Hence the result.

Proof of lemma (9)

Let $P^{*}(F)=p\left(q^{*}(F)\right) q^{*}(F)$ the gross profit made under the full-cost pricing for a value $F \in[0, \hat{F}]$ of the fixed cost. Clearly $P^{*}(0)=P^{v}=p\left(q^{v}\right) q^{v}$. We have $\frac{d P^{*}}{d F}=\left(p+p^{\prime} q\right) \frac{d q^{*}}{d F}$. Derivative $\frac{d P^{*}}{d F}=0$ when $\left(p+p^{\prime} q\right)=0$, namely for $q=q^{m}$ i.e., using relation $(4)$, for $\left((1-n) p+n^{2} F / q\right)=0$. This occurs for a value of the fixed cost $F^{m}=(n-1) P^{m} / n^{2}$. Let us prove that $F^{m} \leq \hat{F}$. Let $\hat{q}(n)$ be the industry output produced under a fixed cost equal to $\hat{F}$, which is defined by (14). Using this relation yields: $p+p^{\prime} q=\left[2 p-p^{\prime \prime} q^{2}\right] /(n+2) \geq 0$, then $\hat{q}(n) \leq q^{m}$ and then $F^{m} \leq \hat{F}$. For this particular value of the fixed cost $F^{m}$, the full-cost pricing oligopoly replicates the standard monopoly case. Consequently, $\frac{d P^{*}}{d F} \geq 0$ for $F \in\left[0, F^{m}\right], \frac{d P^{*}}{d F} \leq 0$ for $F \in\left[F^{m}, \hat{F}\right]$.

Proof of proposition (11)

Lemma (9) implies that there exists $F^{*} \geq F^{m}$ such that $P^{*}\left(F^{*}\right)=P^{v}$ and $P^{*}(F) \geq P^{v}$ for $F \in\left[0, F^{*}\right]$. Let us prove that there exists a number of firms $\hat{n}>1$ such that $F^{*} \geq \hat{F}$,for all $n \geq \hat{n}$,so that the full-cost pricing dominates the integration over $[0, \hat{F}]$. We have $P(\hat{q}(1))=P\left(q^{s}(1)\right)<P^{v}(1)=P^{m}$ and $\lim _{n \rightarrow \infty} P(\hat{q}(n))=P^{m}>P^{v}(\infty)=0$, where $P^{v}(n)$ stands for the vertical integration profit when the number of firm is $n$. It can be checked that $\hat{q}($.$) is an$ increasing function of $n$, then there exists $\hat{n}$ such that $P(\hat{q}(\hat{n}))=P^{v}(\hat{n})$. Then, for $n \geq \hat{n}$, we have $P^{*}(\hat{F})=P(\hat{q}(n)) \geq P^{v}(n)=P^{*}\left(F^{*}\right)$, namely, $F^{*} \geq \hat{F}$. Hence the result. 


\section{PAPIERS}

\section{Laboratoire de Recherche en Gestion \& Economie (LARGE)}

D.R. $n^{\circ} 1$ "Bertrand Oligopoly with decreasing returns to scale", J. Thépot, décembre 1993

D.R. $n^{\circ} 2$ "Sur quelques méthodes d'estimation directe de la structure par terme des taux d'intérêt", P. Roger - N. Rossiensky, janvier 1994

D.R. $n^{\circ} 3$ "Towards a Monopoly Theory in a Managerial Perspective", J. Thépot, mai 1993

D.R. n 4 "Bounded Rationality in Microeconomics", J. Thépot, mai 1993

D.R. n 5 "Apprentissage Théorique et Expérience Professionnelle", J. Thépot, décembre 1993

D.R. $\mathrm{n}^{\circ} 6 \quad$ "Stratégic Consumers in a Duable-Goods Monopoly", J. Thépot, avril 1994

D.R. n 7 "Vendre ou louer; un apport de la théorie des jeux", J. Thépot, avril 1994

D.R. $n^{\circ} 8$ "Default Risk Insurance and Incomplete Markets", Ph. Artzner - FF. Delbaen, juin 1994

D.R. n 9 "Les actions à réinvestissement optionnel du dividende", C. Marie-Jeanne - P. Roger, janvier 1995

D.R. $n^{\circ} 10 \quad$ "Forme optimale des contrats d'assurance en présence de coûts administratifs pour l'assureur", S. Spaeter, février 1995

D.R. n 11 "Une procédure de codage numérique des articles", J. Jeunet, février 1995

D.R. $n^{\circ} 12$ Stabilité d'un diagnostic concurrentiel fondé sur une approche markovienne du comportement de rachat du consommateur", N. Schall, octobre 1995

D.R. $\mathrm{n}^{\circ} 13$ "A direct proof of the coase conjecture", J. Thépot, octobre 1995

D.R. n 14 "Invitation à la stratégie", J. Thépot, décembre 1995

D.R. n 15 "Charity and economic efficiency", J. Thépot, mai 1996 
D.R. $n^{\circ} 16$ "Princing anomalies in financial markets and non linear pricing rules", P. Roger, mars 1996

D.R. n 17 "Non linéarité des coûts de l'assureur, comportement de prudence de l'assuré et contrats optimaux", S. Spaeter, avril 1996

D.R. n 18 "La valeur ajoutée d'un partage de risque et l'optimum de Pareto : une note", L. Eeckhoudt - P. Roger, juin 1996

D.R. $n^{\circ} 19$ "Evaluation of Lot-Sizing Techniques : A robustess and Cost Effectiveness Analysis", J. Jeunet, mars 1996

D.R. n 20 "Entry accommodation with idle capacity", J. Thépot, septembre 1996

D.R. $n^{\circ} 21$ "Différences culturelles et satisfaction des vendeurs : Une comparaison internationale", E. Vauquois-Mathevet - J.Cl. Usunier, novembre 1996

D.R. n²2 "Evaluation des obligations convertibles et options d'échange", A. Schmitt - F. Home, décembre 1996

D.R n 23 "Réduction d'un programme d'optimisation globale des coûts et diminution du temps de calcul, J. Jeunet, décembre 1996

D.R. n 24 "Incertitude, vérifiabilité et observabilité : Une relecture de la théorie de l'agence", J. Thépot, janvier 1997

D.R. $\mathrm{n}^{\circ} 25$ "Financement par augmentation de capital avec asymétrie d'information : l'apport du paiement du dividende en actions", C. Marie-Jeanne, février 1997

D.R. $\mathrm{n}^{\circ} 26$ "Paiement du dividende en actions et théorie du signal", C. Marie-Jeanne, février 1997

D.R. n 27 "Risk aversion and the bid-ask spread", L. Eeckhoudt - P. Roger, avril 1997

D.R. n 28 "De l'utilité de la contrainte d'assurance dans les modèles à un risque et à deux risques", S. Spaeter, septembre 1997

D.R. $\mathrm{n}^{\circ} 29$ "Robustness and cost-effectiveness of lot-sizing techniques under revised demand forecasts", J. Jeunet, juillet 1997

D.R. n 30 "Efficience du marché et comparaison de produits à l'aide des méthodes d'enveloppe (Data envelopment analysis)", S. Chabi, septembre 1997

D.R. n 31 "Qualités de la main-d'œuvre et subventions à l'emploi : Approche microéconomique", J. Calaza - P. Roger, février 1998

D.R n 32 "Probabilité de défaut et spread de taux : Etude empirique du marché français", M. Merli - P. Roger, février 1998

D.R. n 33 "Confiance et Performance : La thèse de Fukuyama", 
J.Cl. Usunier - P. Roger, avril 1998

D.R. $\mathrm{n}^{\circ} 34 \quad$ "Measuring the performance of lot-sizing techniques in uncertain environments", J. Jeunet - N. Jonard, janvier 1998

D.R. n 35 "Mobilité et décison de consommation : premiers résultas dans un cadre monopolistique", Ph. Lapp, octobre 1998

D.R. $\mathrm{n}^{\circ} 36$ "Impact du paiement du dividende en actions sur le transfert de richesse et la dilution du bénéfice par action", C. Marie-Jeanne, octobre 1998

D.R. n 37 "Maximum resale-price-maintenance as Nash condition", J. Thépot, novembre 1998

D.R. $\mathrm{n}^{\circ} 38$ "Properties of bid and ask prices in the rank dependent expected utility model", P. Roger, décembre 1998

D.R. n 39 "Sur la structure par termes des spreads de défaut des obligations », Maxime Merli / Patrick Roger, septembre 1998

D.R. $\mathrm{n}^{\circ} 40$ "Le risque de défaut des obligations : un modèle de défaut temporaire de l'émetteur", Maxime Merli, octobre 1998

D.R. n 41 "The Economics of Doping in Sports", Nicolas Eber / Jacques Thépot, février 1999

D.R. $\mathrm{n}^{\circ} 42$ "Solving large unconstrained multilevel lot-sizing problems using a hybrid genetic algorithm", Jully Jeunet, mars 1999

D.R n 43 "Niveau général des taux et spreads de rendement", Maxime Merli, mars 1999

D.R. $n^{\circ} 44$ "Doping in Sport and Competition Design", Nicolas Eber / Jacques Thépot, septembre 1999

D.R. n 45 "Interactions dans les canaux de distribution", Jacques Thépot, novembre 1999

D.R. n 46 "What sort of balanced scorecard for hospital", Thierry Nobre, novembre 1999

D.R. n 47 "Le contrôle de gestion dans les PME", Thierry Nobre, mars 2000

D.R. $n^{\circ} 48$ "Stock timing using genetic algorithms", Jerzy Korczak - Patrick Roger, avril 2000

D.R. n 49 "On the long run risk in stocks : A west-side story", Patrick Roger, mai 2000

D.R. $n^{\circ} 50$ "Estimation des coûts de transaction sur un marché gouverné par les ordres : Le cas des composantes du CAC40", Laurent Deville, avril 2001

D.R. n 51 "Sur une mesure d'efficience relative dans la théorie du portefeuille de Markowitz", Patrick Roger / Maxime Merli, septembre 2001 
D.R. n 52 "Impact de l'introduction du tracker Master Share CAC 40 sur la relation de parité callput", Laurent Deville, mars 2002

D.R. $n^{\circ} 53$ "Market-making, inventories and martingale pricing", Patrick Roger / Christian At / Laurent Flochel, mai 2002

D.R. n 54 "Tarification au coût complet en concurrence imparfaite", Jean-Luc Netzer / Jacques Thépot, juillet 2002

D.R. n 55 "Is time-diversification efficient for a loss averse investor ?", Patrick Roger, janvier 2003

D.R. n 56 “Dégradations de notations du leader et effets de contagion”, Maxime Merli / Alain Schatt, avril 2003

D.R. $n^{\circ} 57$ “Subjective evaluation, ambiguity and relational contracts”, Brigitte Godbillon, juillet 2003

D.R. n 58 “A View of the European Union as an Evolving Country Portfolio", Pierre-Guillaume Méon / Laurent Weill, juillet 2003

D.R. n 59 “Can Mergers in Europe Help Banks Hedge Against Macroeconomic Risk ?”, Pierre-Guillaume Méon / Laurent Weill, septembre 2003

D.R. $n^{\circ} 60$ "Monetary policy in the presence of asymmetric wage indexation", Giuseppe Diana / Pierre-Guillaume Méon, juillet 2003

D.R. $n^{\circ} 61$ “Concurrence bancaire et taille des conventions de services”, Corentine Le Roy, novembre 2003

D.R. n 62 “Le petit monde du CAC 40”, Sylvie Chabi / Jérôme Maati

D.R. ${ }^{\circ} 63$ “Are Athletes Different? An Experimental Study Based on the Ultimatum Game”, Nicolas Eber / Marc Willinger

D.R. n 64 "Le rôle de l'environnement réglementaire, légal et institutionnel dans la défaillance des banques : Le cas des pays émergents”, Christophe Godlewski, janvier 2004

D.R. n 65 "Etude de la cohérence des ratings de banques avec la probabilité de défaillance bancaire dans les pays émergents”, Christophe Godlewski, Mars 2004

D.R. n 66 "Le comportement des étudiants sur le marché du téléphone mobile : Inertie, captivité ou fidélité ?”, Corentine Le Roy, Mai 2004

D.R. $n^{\circ} 67$ "Insurance and Financial Hedging of Oil Pollution Risks”, André Schmitt / Sandrine Spaeter, September, 2004

D.R. $n^{\circ} 68$ "On the Backwardness in Macroeconomic Performance of European Socialist Economies”, Laurent Weill, September, 2004

D.R. ${ }^{\circ} 69$ "Majority voting with stochastic preferences: The whims of a committee are smaller than the whims of its members”, Pierre-Guillaume Méon, September, 2004 
D.R. $\mathrm{n}^{\circ} 70$ "Modélisation de la prévision de défaillance de la banque : Une application aux banques des pays émergents”, Christophe J. Godlewski, octobre 2004

D.R. $n^{\circ} 71$ "Can bankruptcy law discriminate between heterogeneous firms when information is incomplete ? The case of legal sanctions”, Régis Blazy, october 2004

D.R. n 72 "La performance économique et financière des jeunes entreprises”, Régis Blazy/Bertrand Chopard, octobre 2004

D.R. n 73 “Ex Post Efficiency of bankruptcy procedures : A general normative framework”, Régis Blazy / Bertrand Chopard, novembre 2004

D.R. n 74 “Full cost pricing and organizational structure”, Jacques Thépot, décembre 2004

D.R. $\mathrm{n}^{\circ} 75$ "Prices as strategic substitutes in the Hotelling duopoly”, Jacques Thépot, décembre 2004

D.R. n 76 "Réflexions sur l'extension récente de la statistique de prix et de production à la santé et à l'enseignement”, Damien Broussolle, mars 2005

D. R. $n^{\circ} 77$ "Gestion du risque de crédit dans la banque : Information hard, information soft et manipulation ”, Brigitte Godbillon-Camus / Christophe J. Godlewski

D.R. n 78 "Which Optimal Design For LLDAs”, Marie Pfiffelmann

D.R. n 79 “Jensen and Meckling 30 years after : A game theoretic view”, Jacques Thépot

D.R. n 80 “Organisation artistique et dépendance à l'égard des ressources”, Odile Paulus, novembre 2006

D.R. n 81 "Does collateral help mitigate adverse selection? A cross-country analysis”, Laurent Weill -Christophe J. Godlewski, novembre 2006

D.R. n 82 "Why do banks ask for collateral and which ones ?”, Régis Blazy - Laurent Weill, décembre 2006

D.R. $n^{\circ} 83$ "The peace of work agreement : The emergence and enforcement of a swiss labour market institution”, D. Broussolle, janvier 2006.

D.R. $\mathrm{n}^{\circ} 84$ "The new approach to international trade in services in view of services specificities : Economic and regulation issues”, D. Broussolle, septembre 2006.

D.R. $n^{\circ} 85$ "Does the consciousness of the disposition effect increase the equity premium”?, P. Roger, juin 2007

D.R. n ${ }^{\circ} 86$ "Les déterminants de la décision de syndication bancaire en France”, Ch. J. Godlewski

D.R. n 87 “Syndicated loans in emerging markets”, Ch. J. Godlewski / L. Weill, mars 2007

D.R. $\mathrm{n}^{\circ} 88$ "Hawks and loves in segmented markets : A formal approach to competitive 
aggressiveness”, Claude d’Aspremont / R. Dos Santos Ferreira / J. Thépot, mai 2007

D.R. n 89 “On the optimality of the full cost pricing”, J. Thépot, février 2007. 